\title{
Challenges and prospects of COVID-19 vaccine development based on the progress made in SARS and MERS vaccine development
}

\author{
JUBEDA BEGUM ${ }^{1}$, Nasir Akbar Mir², Kapil Dev², Bidyarani Buyamayum³ ${ }^{3}$ Mohd \\ Yaqoob $\mathrm{Wani}^{4}$, and Meesam Raza ${ }^{2}$ \\ ${ }^{1}$ Govind Ballabh Pant University of Agriculture \& Technology College of Veterinary \& \\ Animal Sciences \\ ${ }^{2}$ Central Avian Research Institute \\ ${ }^{3}$ Jawaharlal Nehru Institute of Medical Sciences Department of Microbiology \\ ${ }^{4}$ Sher-E-Kashmir University of Agricultural Sciences and Technology Faculty of Veterinary \\ Sciences and Animal Husbandry
}

May 21, 2020

\begin{abstract}
The outbreak of COVID-19 as a pandemic has shaken the global health system and economy by their roots. This epidemic is still spreading and showing no signs of decreasing trend. Vaccination is the only effective and economical means to control this pandemic. A number of research institutions and pharmaceutical companies have plunged into the race of vaccine development against COVID-19 which are in various stages of development. An intriguing fact of coronavirus infections is that in every decade of 21st century there is a new major coronavirus epidemic viz. SARS in 2002, MERS in 2012, and now COVID-19; and such epidemics are expected in future too. Since, maximum biological characteristics of SARS-CoV-2 are still obscure the scientists are relying on the information available on SARS-CoV and to some extent on MERS-CoV for designing and development of COVID-19 vaccines. But there is a need of vigorous testing for immunogenicity, safety, efficacy, and level of protection conferred in the hosts. This review focuses on the challenges and prospects of vaccine development against COVID19. It highlights seriousness, bottlenecks in vaccine development, possible vaccine candidates, different vaccine strategies, safety evaluation issues, and vaccine production process pertaining to COVID-19 based on the knowledge acquired on SARS and MERS vaccine development in the past.
\end{abstract}

\section{Introduction}

The outbreak of rapidly spreading severe respiratory disease caused by novel coronavirus (CoV) in December of 2019 in Wuhan, China has put whole world on high alert. The World Health Organization (WHO) named it COVID-19 and declared it a global pandemic on $30^{\text {th }}$ January 2020 (Kim et al., 2020). The disease has spread to more than 200 countries with over 5.12 million cases and more than 3.30 lakh deaths worldwide by $21^{\text {st }}$ May 2020 (Worldometer, 2020). These numbers are still increasing rapidly. The normal life has been disrupted as a result of mandatory lockdowns, isolations, and quarantines in response to COVID19 pandemic and has imposed a serious challenge to global health system and economy (Gorbalenya et al., 2020; Kupferschmidt et al., 2020). The coronaviruses represent an ongoing as well as future threat to human health because of their wide distribution, higher prevalence, higher recombination potential of their genomes, profound genetic diversity, and increasing human-animal interaction (Hui et al., 2020; Zhu et al., 2020). SARS-CoV-2 is relatively a large virus of betacoronavirus genus containing a single-stranded positive-sense RNA genome encapsulated within a membrane envelope (Morse et al., 2020). It is one of the seven discrete coronavirus species capable of causing disease in humans (Zhu et al., 2020). The Coronavirus 
Study Group (CSG) of International Committee on Taxonomy of Viruses (ICTV) changed its name from 2019-nCoV to SARS-CoV-2 because it was found to be a sister virus of severe acute respiratory syndrome coronavirus (SARS-CoV) after genomic analysis (Gorbalenya et al., 2020). The genomic analysis revealed that SARS-CoV-19 genome is more closely related to bat RaTG13 SARS-CoV (96\%) in particular and SARS-CoV (80\%) in general compared to middle east respiratory syndrome (MERS) CoV (54\%) genome (Zhou et al., 2020).

The genomic analysis reveals similarities in receptor-binding motif of SARS-CoV-2 and SARS-CoV which directly binds human receptor protein called angiotensin-converting enzyme-2 (ACE-2) to enter target cells. This has direct bearing on its vaccine design, rapidity of vaccine development, and prediction of its pandemic potential (Kim et al., 2020). Similar to SARS-CoV and MERS-CoV, the predilection site of SARS-CoV-2 is lower respiratory system and viral pneumonia occurs. However, SARS-CoV-2 may also attack gastrointestinal tract, heart, kidney, liver, and central nervous system resulting in death due to multiple organ failure (Zhu et al., 2019). Though, the exact reservoir of SARS-CoV-2 could not be established yet with surety, its humanto-human transmission is now well established, and the verified cases are growing at an alarming rate. After crossing the species barrier, within a month human to human transmission became responsible for widespread and rapid dissemination of virus across the entire population of China with no pre-existing immunity (Chen, 2020; Wu et al., 2020). The current ferocious spread of COVID-19 indicates that SARS-CoV-2 is more transmissible or contagious than SARS-and MERS-CoVs. This grim situation of COVID-19 demands the generation of targeted vaccines and therapies for reducing the associated morbidity and mortality. However, the risk of contracting COVID-19 is highest in healthcare workers, elderly people over 60 years of age, and people suffering from diabetes and hypertension (Huang et al., 2020). Thus, these people need to be prioritized for vaccine trials and licensure (Chen et al., 2020).

\section{Seriousness of COVID-19}

The development of vaccine against SARS-CoV-2 to contain its spread and help eliminate it from human population is a challenging task because there is lack of information on its biological properties, epidemiology, specific immune responses against it (Ahmed et al., 2020). There were 2494 laboratory-confirmed cases of MERS in 27 countries with 858 deaths (fatality rate 34.4\%) and 8098 cases of SARS in 29 countries with 774 deaths (fatality rate 10\%) globally (Zaki et al., 2012). However, COVID-19 brought whole world to stand still because its transmissibility is much ferocious compared to MERS- and SARS-CoVs which has infected more than 5.12 million people including more than 3.30 lakh deaths globally with $6.5 \%$ fatality rate by $20^{\text {th }}$ May 2020 (Worldometer, 2020). Another problematic aspect of SARS-CoV infections is the presence of non-structural protein 'papain-like protease' which behaves like a deubiquitinase and may deubiquinate certain host cell proteins such as interferon factor-3 and nuclear factor kappa B, resulting in immune suppression (Baez-Santos et al., 2015). The potential of transmissibility or spread of viruses is measured in terms of reproductive number (R0). The stochastic and statistical methods have revealed an average R0 of 3.28 for SARS-CoV-2 which exceeds the WHO estimates of 1.4 to 2.5 (Morse et al., 2020). However, the transmissibility of SARS CoV and MERS CoV under hospital setting is comparatively lesser which is indicated by their lower (less than 1) R0 values (Chowell et al., 2015). It means a COVID-19 infected person can transmit the virus to 3.28 other persons, whereas SARS and MERS infected persons can transmit the virus to less than one other person. About $50 \%$ of the COVID-19 cases do not show signs of fever before hospitalization (Guan et al., 2020). Higher R0 value of SARS-CoV-2 along with the transmission from asymptomatic infected individuals (Rothe et al., 2020) indicates that control and prevention of COVID-19 will be challenging without development of a vaccine (Bai et al., 2020; Hu et al., 2020).

The ability of SARS-CoV-2 to mutate is fairly inconclusive. Point mutations were found to be insufficient to create a new virus. According to two recent independent studies in Italy at the "Lazzaro Spallanzani" National Institute for Infectious Diseases (IRCCS) in Rome and the Forensic Division of the Department of Biomedical Sciences and Public Health (DSBSP) at Ancona University Hospital, the genetic sequencing of the virus samples taken from Italian and Chinese patients revealed very small and insignificant variations (Etherington 2020). This is an indication that the SARS-CoV-2 remains fairly stable during the course 
of transmission across multiple individuals and populations. Thus, a vaccine, whenever it arrives, will potentially be effective broadly and for a considerable time of few years at a time (Etherington 2020). Although, no recombination events were detected in SARS-CoV-2 yet (Yu et al., 2020) two coronaviruses co-infecting the same host can make one acquire a genomic fragment of hundreds or thousands base-pair long by recombination which enables the virus to increase its ecological niche or make the leap to a new species (Gralinski et al., 2015). This recombination property of coronaviruses can be the reason for the emergence of SARS-CoV, MERS CoV, and now SARS-CoV-2 since 2002 (Chen, 2020). In a recent study 149 sites of mutations observed across the genome of 103 sequenced strains of SARS-CoV-2 resulted in two subtypes, viz . L and S subtype. Significant differences in geographical distribution, transmission ability, and severity of disease were observed between the two subtypes, which potentially creates further hindrances in vaccine design (Tang et al., 2020). Another study provides a direct evidence that mutations currently occurring in the SARS-CoV-2 genome have functional potential to impact the viral pathogenicity (Yao et al., 2020).

\section{Bottlenecks in COVID-19 vaccine development}

In the past decade a number of sporadic efforts have been made to develop vaccines against human CoVs, but lack of cross-protection rendered by these vaccines due to their extensive sequence diversity has thwarted the progress (Graham et al., 2013). Also, there is the possibility of transmission of SARS-CoV or SARSCoV-2 from animal reservoirs. Thus, the concentration of focus on additional structural proteins, other than spike (S) protein, and conserved epitopes is needed to develop a vaccine which can induce broader heterologous and cross-protective immunity against CoVs within beta-CoV lineage (Saif, 2020). Elucidation of the biological characteristics of any newly emerged virus is instrumental in establishing potential treatments and preventive strategies (Gillim-Ross and Subbarao, 2006). The detailed biological characteristics of SARS-CoV-2 is still unknown and whether it infects only respiratory tract or both respiratory and intestinal tracts is yet to be established. In the latter case oro-nasal vaccine followed by parenteral S protein based booster strategy can be optimum to prevent respiratory and enteric infections along with cessation of fecal and nasal shedding of viruses (Saif, 2020). Another important aspect of biological characteristics of SARS-CoV-2 is the route of dissemination to lungs which is not clear yet. If the lungs get targeted after an upper respiratory tract infection then intranasal live or attenuated vaccine can effectively induce local immunity which could protect the upper as well as lower respiratory tracts and reduce nasal shedding. However, if the lungs are infected via viraemia, then parental vaccine can effectively elicit sufficient virus neutralizing (VN) antibodies in serum to block viraemia which in turn prevents lung infection and virus shedding (Saif, 2020). Furthermore, contribution of cytopathic effect of the virus and immunopathology in the pathogenesis of SARS-CoV infections is unclear which has a direct bearing on the vaccine strategy to be adopted for better protection (Gillim-Ross and Subbarao, 2006). The undesired immunopotentiation in the form of eosinophilic infiltration or increased infectivity was observed following challenge infections after immunizations with whole virus vaccines or even complete spike protein vaccines (Jiang et al., 2012). This constitutes another major obstacle in the development of SARS CoV vaccines.

Though, the vaccine candidates induce serum VN antibodies and systemic cell-mediated immune response in animal models, the correlates of immunity to COVID-19 in humans are still unknown (Saif, 2020). However, in face of the ongoing COVID-19 epidemic vaccine development can be initiated in absence of knowledge on the correlates of immunity by utilizing the strategies developed for vaccine targeting of other viruses. It is because both mucosal and humoral immunity confers protection against most of the respiratory viral infections; however, the role of cell mediated immunity in such protection has not been established yet (Gillim-Ross and Subbarao, 2006). Antibody dependent enhancement (ADE) of CoV infections following vaccination is also a major concern for vaccine development against COVID-19. Though, the mechanism behind ADE is not yet clear it is supposed to be due to sub-neutralizing antibodies which do not have the capacity to completely neutralize viral particles but instead cause enhanced uptake and spread of the viruses by entering Fc receptor expressing cells (Wan et al., 2020; Gillim-Ross and Subbarao, 2006). Currently we do not have any approved treatment or vaccine against the deadly infections of CoVs, including COVID-19 because of lack of interest among pharmaceutical companies and lack of sustained government funding for vaccine development due to disappearance of SARS and decline of MERS (Cyranoski et al., 2020; Saif, 2020). 
Compared to the traditional childhood and adult vaccines the development of vaccines against SARS CoVs for global health security or biodefense are considered less profitable and it has also been the major reason for the lack of interest shown by major multi-national pharmaceutical companies for commercial vaccine development (Chen et al., 2020). The outbreak scenarios are generally short lived and the proportion of people affected is small which does not constitute a significant vaccine market. Furthermore, by the time a new vaccine is available, there might not be any patients available for clinical trials and also no significant market (Dhama et al., 2020). The possible vaccine for COVID-19 must be made available for potential stockpiling because it may not be available for the current pandemic (Chen et al., 2020). However, extensive geographical spread and involvement of large number of people with rapidly increasing cases have sensitized the governments and pharmaceutical companies worldwide to reinforce their efforts against the control of COVID-19. Another aspect of COVID-19 infection is nasal shedding of virus and further transmission in the population which can't be prevented without mucosal immunity. The possible vaccine should not only prevent the deaths but also the nasal virus shedding by boosting mucosal immunity which is generally shortlived and requires multiple booster vaccinations (Saif, 2020). Another bottleneck in the process of vaccine development against COVID-19 is the lack of suitable animal model to test the vaccine efficacy and safety. None of the animal models appropriately mimic the human COVID-19 infection and the potential correlates of infection (Saif, 2020). Though, ferrets mimic the SARS pathogenesis well in humans (Roper and Rehm, 2009) their limitation is less well characterised immune system. On the other hand if SARS susceptible pigs are susceptible to SARS-CoV-2 too, they are supposed to be potentially better model because of their close resemblance to humans in terms of their outbred nature, physiology, metabolism, respiratory system, and immune responses (Vlasova et al., 2016).

\section{Possible vaccine candidates for COVID-19}

Since the SARS-CoV-2 shares a considerable genetic sequence homology and sequence identity of various essential enzymes with SARS-CoV (Hui et al., 2020; Zhu et al., 2020; Perlman 2020; Zhou et al., 2020), the vaccine strategies already built for SARS could potentially facilitate the early design of COVID-19 vaccine (Morse et al., 2020; Chen et al., 2020). Both SARS-CoV-2 and SARS-CoV bind to similar ACE2 receptors of human lungs (Hoffmann et al., 2020; Zhou et al., 2020). Similar to other CoVs, genome of SARS-CoV-2 translates four major structural proteinsviz . nucleocapsid protein (N), spike glycoprotein (S), membrane glycoprotein (M), and envelop protein (E) (Saif, 2020). The S protein is the major focus in vaccine development because it contains receptor binding domain (RBD), functions in viral attachment via S1 subunit, fuses with host cell via S2 subunit, and strongly induces VN antibodies which blocks binding with the host receptor cells in lungs (Zhou et al., 2020). However, M protein has the ability to induce VN antibodies and $\mathrm{N}$ protein contains T-cell epitopes in SARS-CoV, which means they can also act as an efficient vaccine targets (Rauch et al., 2018; Roper and Rehm 2009; Enjuanes et al., 2008).

\subsection{Whole Cell Antigen}

The elements of virus particles, including proteins, lipids, polysaccharides, nucleic acids, and other associated components, constitute whole cell antigens (WCA) (Zhang et al., 2020). The development of killed and liveattenuated vaccines present the whole cell antigens to elicit immune response (Minor et al., 2015). In this regard virus strains of SARS-CoV-2 have been successfully isolated by many institutions globally for development of killed or live-attenuated whole cell vaccine (Zhang et al., 2020). However, it is unavoidable to face more difficulties in quality control and consistency evaluation of such vaccines because of complex compositions antigens and such vaccines require stringent screening and testing for obtaining strains with certified safety (Marohn and Barry, 2013). For example, a mutation (Y6398H) has been introduced into the Orf1a/b polyprotein (p59/nsp14/ExoN) which completely attenuated the virulence of mouse coronavirus (MHV-A59) and MHV-A59 vaccine significantly reduced virus replication in mice at day five following intracerebral inoculation (Morse et al., 2020).

4.2 Spike protein $(\mathrm{S})$

The $\mathrm{S}$ protein is the most promising antigen for production of SARS-CoV-2 vaccine. It is a surface protein 
directly recognized by host immune system (Wrapp et al., 2020). It mediates binding with ACE2 receptor in human lungs which is an essential step for virus fusion and entry into host cell to establish subsequent pathogenicity in lungs (Wrapp et al., 2020; Lan et al., 2020). Also, the S protein based vaccines developed against SARS-CoV and MERS-CoV were found to be effective to a large extent (Zhou et al., 2018; Zhang et al., 2020). The S protein in SARS-CoV-2 is cleaved into amino-terminal S1 and carboxy-terminal S2 subunits which is not the case with SARS-CoV (Saif, 2020). The S1 subunit is further composed of two domains; N-terminal domain (NTD) and C-terminal domain (CTD). RBD is located in the CTD and S2 subunit contains the basic elements required for membrane fusion (Zhang et al., 2020). The full length S protein and its antigenic components have the potential to serve as important candidates for vaccine development against COVID-19 (Jiaming et al., 2017; Zhou et al., 2018). Though, the comparison of full length S protein sequences of SARS-CoV-2 and SARS-CoV revealed maximum variability in S1 subunit of S protein, it is still a promising target for vaccine development against COVID-19 (Yu et al., 2020; Morse et al., 2020).

The native $S$ proteins exist as a trimeric form on the surface of virus. However, when its ectodomain or $\mathrm{S} 1$ is expressed as a recombinant protein in eukaryotic systems, the protein exists predominantly in a monomeric form (Li et al., 2013; Kim et al., 2020). Recreating the trimeric structure has been shown to increase immunogenicity which depicts the importance of mimicking the native trimeric structure $(\mathrm{Li}$ et al., 2013; Krammer et al., 2012; Kim et al., 2020). Using its patented Trimer-Tag ${ }^{\circledR}$ technology, Clover Biopharmaceuticals produced a COVID-19 S-Trimer subunit vaccine by a rapid mammalian cell-culture based expression system which resembles the native trimeric viral spike. Having extensive commercial-scale GMP biomanufacturing capabilities in China, Clover is expected to rapidly scale-up and produce large-quantities of this new coronavirus vaccine having GSK2 adjuvant (Liu et al., 2017; Glaxo Smit Kline, 2020; Zhang et al., 2020). Based on their experience with MERS and SARS, Novavax developed their COVID-19 candidate vaccine targeting the $\mathrm{S}$ protein of SARS-CoV-2 by using their recombinant nanoparticle vaccine technology along with their proprietary adjuvant Matrix-MTM (Novavax, 2020). After single shot immunization high immunogenicity was exhibited in animal models with significant display of S protein-specific antibodies, antibodies blocking the binding of S protein to the receptor, and wild-type VN antibodies. First human trial is expected by mid-May.

A SARS coronavirus vaccine based on a recombinant full-length trimeric S protein exhibited native antigenicity, specific binding to soluble ACE2 receptor, adequate protection against challenge infection in animal model (Morse et al., 2020). The vaccines based on full-length S protein are supposed to present the correct conformation of the protein, provide more epitopes, and exhibit higher immunogenicity (Zhang et al., 2020) but in case of SARS-CoV some vaccines mediate enhancement of viral infection which has raised safety concerns over full-length S protein based vaccines (Jaume et al., 2012; Wang et al., 2020). Furthermore, the $\mathrm{S}$ protein based subunit vaccines have been reported to produce higher VN antibody titers and better protection than live-attenuated SARS-CoV, full-length S protein, and DNA-based S protein vaccines (Buchholz et al., 2004; Morse et al., 2020). However, mRNA vaccines put forward by Moderna are composed of mRNAs which encode for full-length S, S1, or S2 proteins from SARS-CoV and MERS-CoV and are carried in cationic lipid nanoparticles (Morse et al., 2020). Higher VN antibody titers were observed in mice vaccinated with mRNA encoding full-length S protein compared to mRNA encoding S protein or S2 subunit and in New Zealand white rabbits full-length S protein reduced more than $90 \%$ of viral load in lungs along with significant induction of VN antibody against MERS-CoV.

RBD of S protein comprises of major critical neutralizing domain which directly interacts with the ACE2 receptor of host cells and immunization with RBD based vaccine blocks this interaction by inducing specific VN antibodies (Zhang et al., 2020; Zhou et al., 2019). Since, these vaccines exert strong protective immunity against viral infection most of the COVID-19 subunit vaccines under process are based on RBD antigen (Zhang et al., 2020; Wang et al., 2020). As a candidate for vaccine against SARS-CoV it has been demonstrated that RBD, consisting of multiple conformational neutralizing epitopes, induced higher VN antibody titer (Zhu et al., 2013). RBD of S protein is considered more suitable because it is relatively more conserved than the S1 subunit and contains multiple conformational neutralizing epitopes (Jiang et al., 2005; Zhang et al., 2020). However, S1 subunit itself induces strong immune response and protection against CoV infection 
(Li et al., 2013; Adney et al., 2019; Zhang et al., 2020). On the other hand, S2 subunit protein has conserved amino acid sequence and high homology among different virus strains which makes it a potential target for development of a broad spectrum vaccine effective against divergent virus strains (Elshabrawy et al., 2012; Zhou et al., 2018; Wang et al., 2020). Though, S2 subunit as well as NTD have the potential to elicit VN antibodies, they are less immunogenic, exhibit lower antibody titers, cellular immune responses, and protection compared to other antigenic determinants (Jiaming et al., 2017). Thus, based on the above facts RBD and S1 protein are the critical vaccine candidates for SARS-CoV as well as SARS-CoV-2.

\subsection{Nucleocapsid protein $(\mathrm{N})$}

The $\mathrm{N}$ protein is highly conserved and most abundant protein in coronavirus which is actively involved in viral propagation (McBride et al., 2014) and is a potential additional target for the development of SARS and MERS vaccines. It is highly antigenic and induced specific humoral and cellular immune responses in convalescent-phase SARS patients (Leung et al., 2004) and C57BL/6 mice (Kim et al., 2004). However, in contrast, it has been reported that it does not elicit VN antibodies to block virus binding the ACE2 receptor and prevent viral infection (Liu et al., 2006; Zheng et al., 2009). Also, in hamsters N protein immunization did not induce VN antibodies and provided no protection against SARS-CoV (Buchholz et al., 2004). These conflicting results suggest that $\mathrm{N}$ protein is not a reliable candidate for vaccine development for SARS-CoV but has a good diagnostic value because of its high immunogenicity (Zhang et al., 2020).

\subsection{Membrane protein (M)}

$\mathrm{M}$ protein is the most abundant and highly conserved trans-membrane glycoprotein on the surface of SARS$\mathrm{CoV}$ involved in virus assembly (Neuman et al., 2011). SARS-CoV M protein-derived peptides (M-131 and M-132-161), identified in sera of convalescent-phase SARS patients, have good immunogenicity to induce high titer of specific IgG antibody response in immunized rabbits (He et al., 2005a). The full length $\mathrm{M}$ protein has been reported to elicit VN antibodies efficiently in SARS patients upon immunization (Pang et al., 2004). The $\mathrm{T}$ cell epitope cluster containing domain of $\mathrm{M}$ protein has been reported to elicit a strong cellular immune response (Liu et al., 2010). Though, this protein has not been investigated much for its protective efficacy against SARS-CoV infection, the above factors suggest its potential as a possible vaccine candidate against SARS-CoV-2.

\subsection{Envelop protein (E)}

The $\mathrm{E}$ protein is the smallest of the major structural proteins of CoVs. It is an important virulence factor and its knocking out has shown marked reduction of inflammatory factors IL-1 $\beta$, TNF, and IL-6 (Nieto-Torres et al., 2014). The potential B cell epitopes of the E protein of MERS-CoV are considered as probable vaccine protective targets which have the capacity to induce both T-cell and neutralizing antibody responses (Shi et al., 2015; Xie et al., 2018). However, its immunogenicity is quite limited compared to other structural proteins (Zhang et al., 2020) and has been least investigated for vaccine development due to which it cannot considered as a suitable vaccine candidate for COVID-19.

\section{5. $T$ cell and $B$ cell epitopes as target vaccine candidates for COVID-19}

Humoral immunity by B-cell antibodies and cellular immunity by T-cells are important for effective vaccines (Rappuoli et al., 2019). On one hand, VN antibodies block the entry of viruses into human cells and on the other hand, cytotoxic CD8 T-cells and helper CD4 T-cells fully clear viruses from the infected cells (Fast and Chen, 2020). Researchers from the Hong Kong University of Science and Technology (HKUST) investigated the B-cell and T-cell S and N protein epitopes arising in response to SARS-CoV to find biomarkers that could be incorporated into vaccines to trigger an immune response against SARS-CoV-2 (Balfour, 2020). Similar to SARS-CoV, the SARS-CoV-2 S protein is likely to be immunogenic which carries several T-cell and B-cell epitopes (Fast and Chen 2020). Since $23 \%$ and $16 \%$ of known SARS-CoV T-cell and B-cell epitopes mapped identically with that of SARS-CoV-2, respectively, and no mutations have been observed in these SARS$\mathrm{CoV}-2$ epitopes, harnessing the vaccine candidate value of these epitopes may offers a significant protection against COVID-19 (Ahmed et al., 2020). Also, the high genetic similarity between SARS-CoV-2 and SARS- 
$\mathrm{CoV}$ indicates that the vaccines developed for SARS-CoV may exhibit cross-reactivity with SARS-CoV-2 (Jiang et al., 2020; Dhama et al., 2020). Profound antibody response has been generated against S protein in mouse models (Deming et al., 2006; Graham et al., 2012) and N protein in SARS-CoV infected patients (Liu et al., 2004). Though being effective, the antibody response developed in convalescent SARS patients was found to be short-lived in nature (Tang et al., 2011).

However, compared to this humoral response T-cell response against the structural proteins of SARS-CoV was found to be more dominant and provide long-term protection which makes the T-cell epitopes more interesting prospective vaccine candidate against SARS-CoV infections (Tang et al., 2011; Ng et al., 2016; Liu et al., 2017). The potential of cross-reactivity among CoVs was confirmed in a study based on similarity in the T-cell epitopes of SARS- and MERS-CoVs which expounds the possibility of broad spectrum universal CoV vaccine (Liu et al., 2017). However, Ahmed et al., (2020) argues that the prospects of T-cell epitopes in vaccine production against COVID-19 is more promising compared to B-cell epitopes. It is because of higher percentage of SARS-CoV derived T-cell epitopes that map identically with that of SARS-CoV-2, larger population expected to be covered, and long term protection conferred (Tang et al., 2011; Ng et al., 2016). Furthermore, SARS-CoV derived antibodies targeting the RBD of S1 subunit of SARS-CoV-2 S protein may not be effective due to the large genetic mismatches observed in known structural epitopes targeting this domain (Wrapp et al., 2020; Tian et al., 2020; Ahmed et al., 2020).

\section{Vaccine strategies against COVID-19}

Since, the SARS-CoV-2 reservoir has not been established yet its re-emergence or that of its related virus in future is expected to infect the human populations again. Only the vaccine development targeting this virus will help contain the virus before it cripples the global health and economic system again as observed in the current pandemic. Currently, we do not have any $\mathrm{CoV}$ vaccine, approved or licensed, to prevent respiratory infections in humans. Because of increasing COVID-19 cases at an alarming speed, continuous appearance of MERS cases, threat of re-emergence of SARS, and the emergence of new CoV infections in future (Wang et al., 2020), it is important to target the development of a broad spectrum vaccine with adequate safety and efficacy to prevent such infections in humans. Several vaccines have been proposed for COVID-19 which are in various stages of development (WHO, 2020). Different vaccine strategies have been adopted by various institutions and companies based on their previous technological platforms, resource base, and demands imposed by the current pandemic. The approaches and strategies adopted for SARS and MERS vaccines will provide intriguing inputs for the speedy design and development COVID-19 vaccines (Wang et al., 2020). The use of new technologies like recombinant viral vectors and nucleic acid vaccines provide universal vaccine platforms which conveniently develop and present new antigenic targets from emerging viruses (Rauch et al., 2018). Upon immunization they mimic attenuated virus vaccines which infects host cells and induce endogenously produced antigenic proteins, respectively, which elicit antibody as well as T-cell immune responses (Rauch et al., 2018; Roper and Rehm, 2009; Enjuanes et al., 2008; Schindewolf and Menachery 2019). Most of the nucleic acid vaccines based on either DNA or mRNA constructs encode for S or RBD proteins in host cells (Roper and Rehm, 2009; Enjuanes et al., 2008; Schindewolf and Menachery 2019) and the similar proteins are prime targets of subunit vaccines for SARS-CoV and MERS-CoV which can be extended to SARS-CoV-2 too (Jiang et al., 2020). Currently, most of the COVID-19 candidate vaccines under development are $\mathrm{S}$ protein or RBD subunit vaccines and vector vaccines which express mainly $\mathrm{S}$ protein or the RBD (WHO, 2020). The criteria for any successful vaccine development are safety, efficacy, and duration of immunity. However, in case of pandemics like COVID-19 rapid development of vaccine at a very high production capacity is another important criterion (Rauch et al., 2018). When it comes to traditional inactivated and attenuated vaccines, the rapid production of such vaccines in large quantities under biosafety level-3 conditions is difficult which renders them less suitable as first-generation vaccines under pandemic conditions (Saif, 2020).

\subsection{Whole virus vaccines}

Whole virus vaccines, either killed or live-attenuated, have multiple antigenic components which potentially induce wide variety of immunologic effectors in the host against virus (Sharma et al., 2011). The reverse 
genetics mechanism is adopted to generate live attenuated $\mathrm{CoV}$ vaccines by deletion of key virulence factors. Such vaccines are immunologically highly efficient and exert wider cross protection which potentially induce mucosal, systemic, humoral, and cell mediated immunity upon immunization (Roper and Rehm, 2009; Enjuanes et al., 2008; Saif 2017; Schindewolf and Menachery 2019). The inherent immunogenicity and ability of whole virus vaccines to stimulate toll-like receptors (TLRs) like TLR 3, TLR 7/8, and TLR 9 is their major advantage (Chen et al., 2020). These vaccines are considered most efficient in primary vaccination of naive hosts followed by parenteral booster vaccines for better protection (Saif, 2017). This reverse genetic technique can be an ideal approach for successful development of attenuated COVID-19 vaccine for priming immune responses in naive hosts followed by parenteral heterologous $\mathrm{S}$ or $\mathrm{N}$ protein booster vaccine to possibly elicit cross protection against strains within beta-CoV genus (Ng and Tan, 2017; Saif, 2020). Earlier, $\beta$-propriolactone inactivated SARS CoV whole-virus vaccine adjuvanted with MF59 elicited promising VN antibody titer in mice and got approval for human use in Europe (Stadler et al., 2005; Gillim-Ross and Subbarao, 2006).

Globally, several institutions have successfully isolated the virus strains of SARS-CoV-2 and started research on the prospects of vaccine development (Zhang et al., 2020). For example, Codagenix, Inc. collaborated with the Serum Institute of India, Ltd. to develop a live-attenuated vaccine against SARS-CoV-2 by "codon deoptimization technology" (Shieber, 2020). Similarly, Johnson \& Johnson will attempt to deactivate SARS$\mathrm{CoV}-2$ which switches off its virulence factors but retains its ability to stimulate immune system. According to the company statement human trials are expected by September 2020 (Ryan, 2020). Also, the researchers at University of Hong Kong developed a live influenza vaccine that expresses SARS-CoV-2 proteins (Cheung 2020). However, the development of live virus vaccines require propagation of high titers of infectious virus and extensive testing to ensure safety which warrants the requirement of biosafety level-3 for production (Gilim-Ross and Subbarao, 2006; Chen et al., 2020). The ADE problem of CoV vaccines is particularly prominent with live or killed whole virus SARS coronavirus vaccines (Jiang et al., 2012; Chen et al., 2020) and incomplete inactivation of virus vaccine is a potential public health threat as well (Gillim-Ross and Subbarao, 2006).

\subsection{Subunit vaccines}

Subunit vaccines, safer and easier to produce, present one or few antigens to host with strong immunogenicity, but they require adjuvants to elicit a strong protective immune response (Zhang et al., 2020). Subunit vaccines against SARS elicit immune response against the $S$ protein which prevents binding of virus with ACE2 receptor in host lungs (Jiang et al., 2012) and currently, almost all RBD subunit vaccines in process of development against SARS-CoV-2 are based on S protein or RBD of S1 protein as antigens (WHO, 2020; Zhang et al., 2020). The SARS-CoV and SARS-CoV-2 RBDs present the similarity of over $80 \%$ in their amino acid sequence which offers an opportunity to develop either of the proteins as subunit vaccine for both and it also offer an advantage of minimum immunopotentiation in the host (Chen et al., 2020; Jiang et al., 2012). After emergence of SARS in 2002, a subunit vaccine consisting of a soluble baculovirus-expressed NTD of S1 protein was developed and immunization in mice elicited high VN antibody titers which conferred highly effective protection against subsequent intranasal challenge with SARS-CoV (Bisht et al., 2004). At Baylor College of Medicine, Texas Children's Hospital Centre for Vaccine Development developed and tested a subunit vaccine based on the RBD of S1 protein of SARS-CoV which elicited a strong immunity on homologous virus challenge when formulated in alum (Jiang et al., 2012; Chen et al., 2017; Chen et al., 2014). Although some full-length S-proteins of SARS have been observed to elicit increased infectivity and eosinophilic infiltration, Clover Biopharmaceuticals Inc. developed a trimerized S protein based subunit vaccine against SARS-CoV-2 using its Trimer-Tag $@$ technology (Chen et al., 2020; Clover biopharmaceuticals, 2020). Also, Novavax Inc. is assessing the efficacy of its newly developed nanoparticle vaccine candidates based on $\mathrm{S}$ protein to arrive at a suitable vaccine candidate for future human trials expected in mid-May (Novavax, 2020). Similarly, the other units which are the process of subunit vaccines development against SARS-CoV-2 are Johnson \& Johnson, Pasteur Institute, and Chongquing Zhifei Biological Products Co. Ltd. (Zhang et al., 2020). 


\section{3 mRNA vaccines}

As a result of tremendous advancement in biotechnology, mRNA vaccines represent a significant upgrade over conventional vaccine strategies owing to their higher potency, short production cycles, low-cost manufacturing, and safe administration (Pardi et al., 2018). The sequential events in the process of mRNA vaccine development constitutes antigen selection, sequence analysis and optimization, screening of modified nucleotides, selection of delivery system, immune response and safety evaluation tests (Jahanafrooz et al., 2020). A potential advantage of mRNA vaccines is the convenient availability of a portable mRNA 'printing' facility for the production of mRNA is large quantities (Saif, 2020). The use of nanotechnology enhances the delivery of mRNA vaccine via intramuscular or intradermal route by using lipid nanoparticle coating (Rauch et al., 2018; Saif, 2020). Thus, a number of major biotech companies have ventured into COVID-19 vaccine development using the advanced nucleic acid vaccine platforms, such Moderna and CureVac (Chen et al., 2020). Since, no mRNA vaccine has been licenced till date its quality and safety testing may take more than the expected time (Zhang et al., 2020). However, with advancement in nucleic acid technologies the nucleic acid vaccine performance in humans has improved due to new modifications and formulations and this approach is expected to ensure the first licenced human nucleic acid vaccine very soon (Chen et al., 2020). In the race of mRNA vaccine development SARS-CoV-2 mRNA vaccine (mRNA-1273) developed by Moderna is the most talked about. It is a lipid nanoparticle- encapsulated mRNA vaccine encoding for $\mathrm{S}$ protein. Its manufacturing cost is supported by the Coalition of the Epidemic Preparedness Innovations. This vaccine is currently in phase I open-label dose-ranging trial in humans at Kaiser Permanente Washington Health Research Institute in Seattle and phase II trial to assess the safety, reactogenicity, and immunogenicity is expected in June month of this year (Moderna, 2020). Further, the triangular collaboration between Fudan University, Shanghai Jiaotong University, and Bluebird Biopharmaceutical Company has come up with two different strategies for the development of SARS-CoV-2 mRNA vaccine. The first one targets $\mathrm{S}$ protein and RBD of S1 of SARS-CoV-2 and second one uses mRNA to express virus-like particles in vivo (Zhang et al., 2020). The other notable companies and institutions who ventured into SARS-CoV-2 mRNA vaccine development and are in different stages of development are CureVac AG, Stermirna Therapeutics, BDGENE Therapeutics, Guanhao Biotech, ZY Therapeutics Inc., CanSino Biologics Inc., Baylor College of Medicine, University of Texas, etc.

\subsection{DNA vaccines}

A typical DNA vaccine is a plasmid DNA molecule which encodes for one or multiple antigens to be presented to the host immune system. They possess the advantages of stability and efficient delivery over mRNA vaccines but they possess the risk of vector mutations and integration into the host genome because they are required to enter the nucleus (Zhang et al., 2020; Liu 2019; Rauch et al., 2018). DNA vaccines targeting the antigenic fragments such as S, N, M, and E proteins of SARS-CoV have been evaluated in mice (He et al., 2005b; Jin et al., 2005; Kim et al., 2004) and the DNA vaccines targeting S, M, and N proteins induced humoral as well as cellular immune response. However, variation in the level of immunity between the target proteins was observed (Jin et al., 2005). An approach of combining different vaccine strategies is considered superior in eliciting an efficient immune response and protection against SARS-CoV (Woo et al., 2005; Zakhartchouk et al., 2005). For example, administration of S protein coding DNA vaccine, followed by whole virus inactivated vaccine or $\mathrm{S}$ peptide vaccine, elicited more powerful humoral and cell-mediated immune responses in mice than either type alone (Roper and Rehm, 2009; Enjuanes et al., 2008; Zakhartchouk et al., 2005; Woo et al., 2005). The DNA vaccines are considered safe, stable, and can be produced rapidly but their immunogenicity and efficiency of eliciting immune response in humans has not been proven yet. The strategy of DNA vaccination was initiated in 1993 with promising results against influenza viruses but the same results could not be translated in humans yet (Chen et al., 2020). However, several biotech companies with advanced nucleic acid vaccine platforms, such as Inovio Pharmaceuticals, Applied DNA Sciences Subsidiary, LineaRx, and Takis Biotech have taken up DNA vaccine development against COVID-19 (Chen et al., 2020; Zhang et al., 2020). There are two DNA vaccines under process of development against COVID-19. The DNA vaccine candidate, INO-4800, developed by Inovio Pharmaceuticals is in phase I clinical trials in the US and phase II clinical trials are expected this summer. Similarly, a linear DNA vaccine candidate against SARS-CoV-2, 
developed as result of collaboration between Applied DNA Science Subsidiary, LineaRx, and Takis Biotech, is in preclinical stage.

\subsection{Live vector vaccines}

Live vector vaccines constitute the live viruses acting as vectors which express the desired heterologous antigens of targeted viruses. This vaccine strategy combines the strong immunogenicity property of live attenuated vaccines and the safety aspect of subunit vaccines, and this strategy is widely used to induce cellular immunity in host (Zhang et al., 2020). Reverse genetics approach has been successfully used to develop live-attenuated viruses by inactivating exonuclease effects of non-structural protein 14 (nsp 14) or by deletion of the structural envelop protein in SARS-CoV (Graham et al., 2013). By adopting the similar approach, $\mathrm{H}$ strain of avian infectious bronchitis virus (IBV) can be used to express the antigenic determinants of SARS-CoV and elicit humoral as well as cell-mediated immunity (Bijlenga, 2005; Dhama et al., 2020). Thus, following safety evaluation in non-human primates, the recombinant avian IBV can act as a prospective vector vaccine for SARS-CoV-2 (Zhang and Liu, 2020). A number of research institutions and pharmaceutical companies have taken up the process of live vector vaccine development for SARS-CoV-2. Greffex Inc. and Tonix Pharmaceuticals are working on the development of adenovirus vector and horsepox virus vector (TNX-1800) vaccines against SARS-CoV-2, respectively. However, using Greffex Vector Platform Greffex has already advanced to the stage of animal testing (Zhang et al., 2020). Similarly, Johnson \& Johnson took

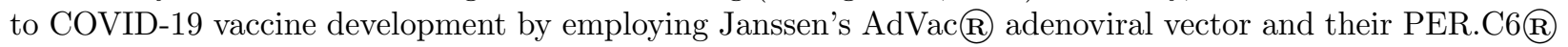
cell line technology (J\&J, 2020; Cheung, 2020).

The recombinant adenovirus vectors of chimpanzee origin (CHAd63) have been used for development of SARS and MERS vaccines to overcome the widespread pre-existing immunity against human adenoviruses. The CHAd63 expresses SARS-CoV S or N protein or MERS-CoV S protein and was shown to confer different levels of protection in mice, ferret, and nonhuman primates following challenge (Roper and Rehm, 2009; Enjuanes et al., 2008; Schindewolf and Menachery, 2019). The immunization of BALB/c mice with recombinant adenovirus vector vaccine expressing MERS-CoV S protein induced systemic and mucosal antibodies along with memory T-cell response in lungs which indicates the potential of this vaccine to confer protection against MERS-CoV (Kim et al., 2019). Other vectors for SARS and MERS vaccines which could be the prospective vectors for COVID-19 vaccines include modified vaccinia ankara (MVA), parainfluenza virus, measles virus, Newcastle disease virus, and vesicular stomatitis virus which have been shown to express $\mathrm{S}$ and/or N proteins of SARS- and MERS-CoV (Roper and Rehm, 2009; Enjuanes et al., 2008; Schindewolf and Menachery, 2019). Even the use of Rabies virus as viral vector has shown promising results in BALB/c mice against MERS-CoV by expressing S protein of the same and eliciting higher levels of cellular immunity and earlier antibody response ( $\mathrm{Li}$ et al., 2020). After the outbreak of SARS in 2002, a live attenuated Chimeric bovine/human parainfluenza virus 3 (BHPIV3) was utilized as a vector for the expression of S, N, M, and $\mathrm{E}$ proteins of SARS-CoV. However, only vector vaccine expressing S protein was successful in providing protection against SARS in hamsters (Buchholz et al., 2004; Gillim-Ross and Subbarao, 2006). Also, the vaccines expressing multiple proteins other than $\mathrm{S}$ protein could not provide protection to hamsters which suggests that only $\mathrm{S}$ protein is a promising antigen in vectored vaccines. On the other hand, vaccination of African green monkey by BHPIV3 vector expressing S protein of SARS-CoV conferred protection as well as prevented nasal virus shedding following challenge (Bukreyev et al., 2004).

\section{Safety evaluation issues}

Safety is a major concern of vaccines which needs due consideration while development, otherwise, failure of approval by a regulating agency is a certified outcome of the process. The formalin and UV-inactivated SARS vaccine and $\gamma$-radiation inactivated MERS vaccine developed a peculiar eosinophil-related lung pathology in mice following challenge. But when toll-like receptor agonists were associated with SARS vaccine there was reduction in lung pathology (Roper and Rehm, 2009; Schindewolf and Menachery, 2019). Another study with ferrets reported liver pathology following vaccination with modified vaccinia ankara (MVA) expressing S protein, however, no other studies supported such claims till date (Roper and Rehm, 2009). For COVID-19 vaccine development process $\mathrm{S}$ protein is the most targeted candidate antigen. Its biological characteristics, 
other than receptor binding and membrane fusion, are obscure (Zhang et al., 2020) which may potentially exert other biological activities affecting the vaccine safety and efficacy. On the other hand, ADE is a longterm obstacle in the development of vaccines against CoVs. This ADE has been observed with full-length $\mathrm{S}$ protein and is considered to be associated with the production of S protein specific antibodies (Wang et al., 2016; Liu et al., 2019). In hamsters SARS S protein based vaccine demonstrated ADE post-challenge but no such effect was observed in mice with S protein nanoparticle MERS vaccine following challenge dose (Roper and Rehm, 2009; Schindewolf and Menachery, 2019). However, it not clear yet which particular domain and which key amino acids in S protein of SARS-CoV are involved in the above safety issues with $\mathrm{S}$ protein vaccines. Therefore, a more basic research need to be carried out on the structure and function of this protein and mutations can be introduced at places in this protein to do away with such adverse effects (Zhang et al., 2020). The deficiencies and inconsistencies in the results pertaining to lung pathology, liver damage, and $\mathrm{ADE}$ observed in $\mathrm{CoV}$ infections among animal models necessitates an improved understanding of the biological basis for their occurrence and a better knowledge of human immunology to avoid similar reactions in humans.

\section{Vaccine production process and COVID-19}

Vaccines are the most effective means to prevent and control infectious diseases economically (Remy et al., 2014). In this pandemic all eyes are on the research institutions and the pharmaceutical companies involved in COVID-19 vaccine development. However, the vaccine production process has to follow the set stringent principles laid by various regulating agencies and a successful SARS-CoV-2 vaccine could not be achieved overnight. The biological characteristics of SARS-CoV-2 such as epidemiology, structural basis, pathogenesis, correlates of immunity, immune-pathologies, etc are still unclear (Zhang et al., 2020). Generally, normal vaccine development takes a decade or two with very less success rate but there is a broad consensus between the scientists worldwide regarding the availability of vaccine against SARS-CoV-2 which is expected to be 12-18 moths away (Dresden, 2020). It is because the identification of SARS-CoV-2 was done within 3 months of its spread and the study of its other biological characteristics is undergoing very vigorously to develop the whole information which will potentially facilitate the rapid development of its vaccine. Globally, confirmed COVID-19 cases are still increasing at an alarming rate and it may potentially become a flu-like seasonal disease and remain in coexistence with human beings for a long time (Neher et al., 2020). Thus, vaccine development is necessary even if it is occurring at a slower pace than the spreading of COVID-19 pandemic. Once a potential vaccine is announced by a researcher, a prospective producer pharmaceutical company has to submit an application to a regulatory authority such as Food and Drug Administration (FDA) for investigation of the new vaccine. The application must describe the vaccine, its manufacturing process, its safety, and efficacy in animal testing (Dresden, 2020). Broadly the vaccine production process can be classified into following stages (Ryan, 2020):

a) Vaccine design: A researcher studies the relevant pathogen characteristics, selects most suitable antigenic fragment, and makes that antigen get expressed preferably to get recognized by host immune system.

b) Animal studies: The new proposed vaccine is tested in animal models to study immune responses, efficacy, and safety upon immunization. The correlates of immunity, immuno-pathologies, and level of protection conferred on challenge are also studied.

c) Clinical trials (phase I): After successfully passing the animal studies similar investigations are carried out in a small cohort of patients or volunteers. The dose and side effects of the vaccine are also studied.

d) Clinical trials (phase II): This stage involves a deeper analysis of vaccine biology and mechanism of action over a larger cohort of patients.

e) Clinical trials (phase III): This phase is similar to phase II but has a greater coverage of people under testing over a longer period of time to generate large amount of data to draw valid statistical conclusions. This phase also explores any possible late adverse effects of immunization.

f) Regulatory approval: The regulatory agency takes a final call regarding approval of the studied vaccine 
as a treatment option for the disease. Regulatory agency strictly carries out scrutiny of the evidences and the data on animal and human trials with the proposed vaccine to make a final decision on its suitability as a treatment option. Traditionally, it takes a decade or two for a new vaccine to go from a design to approval stage (Ryan, 2020) but the process of vaccine development against COVID-19 has briskly reached the phase II clinical trial at various places worldwide and it is expected to be the fastest vaccine ever produced in human history.

\section{Conclusions}

Because of structural similarity and binding to same host cell receptors, SARS-CoV-2 and SARS-CoV may potentially share similar disease pathogenesis and exhibit cross-immunity to some extent. The understanding of biological characteristics of SARS-CoV and technological advancement in vaccine production could make first-generation COVID-19 vaccine available very soon, though it may not be available to cater the current pandemic. There are about 7 or 8 SARS-CoV-2 antigenic candidates which could be employed for vaccine development. But there is a need of vigorous testing for immunogenicity, safety, efficacy, and level of protection conferred in the hosts. Hastening the deployment of first-generation vaccine for current pandemic could be achieved by propelling the nucleic acid based priming vaccines followed by boosters of protein based vaccines to curtail the mortality in high risk groups such as elderly persons and health care workers. Parallel to this, more potent and efficient second-generation vaccine production for future should be carried out to prevent disease spread, mortalities, and viral shedding. Another intriguing aspect of CoVs is that in every decade of $21^{\text {st }}$ century there is a new major CoV epidemic viz. SARS in 2002, MERS in 2012, and now COVID-19. Such epidemics are expected in future too. Among CoVs S2 subunit is highly conserved and homologous which is a potential target for development of a pan-CoV vaccines after enhancing its immunogenicity and it can be used across all population worldwide and against divergent strains of CoVs. Thus, there is a need to mobilize the international funding agencies to support the development, manufacture, and stockpiling of $\mathrm{CoV}$ vaccines.

\section{Conflict of interest}

The authors declare no conflict of interest of any kind arising out this manuscript

\section{Ethical statement}

No ethical approval was required as this is a review article with no original research data.

\section{Data availability statement}

Data sharing is not applicable to this article as no new data were created or analyzed in this study.

\section{References}

Ahmed, S. F., Quadeer, A. A., \& McKay, M. R. (2020). Preliminary identification of potential vaccine targets for the COVID-19 Coronavirus (SARS-CoV-2) based on SARS-CoV immunological studies. Viruses, $12(3), \mathrm{E} 254$.

Baez-Santos, Y. M., St. John, S. E., \& Mesecar, A. D. (2015). The SARS- coronavirus papain-like protease: structure, function and inhibition by designed antiviral compounds. Antiviral Research, 115, 21-38.

Bai. Y., Yao, L., Wei, T., Tian, F., Jin, D. Y., Chen, L., \& Wang, M. (2020). Presumed Asymptomatic Carrier Transmission of COVID-19. Journal of American Medical Association. https://doi.org/10.1001/jama.2020.2565.

Balfour, H. (2020). Coronavirus update: recent developments in vaccine research. Drug Target Review. https://www.drugtargetreview.com/news/56607/coronavirus-update-recent-developments-in-vaccineresearch/ Accessed online 06/04/2020 12:09 PM

Bijlenga, G. (2005). Proposal for vaccination against SARS coronavirus using avian infectious bronchitis virus strain H from The Netherlands. Journal of Infection 51(3), 263-265. 
Bisht, H., Roberts, A., Vogel, L., Bukreyev, A., Collins, P. L., Murphy, B. R., Subbarao, K., \& Moss, B. ( 2004). Severe acute respiratory syndrome corona- virus spike protein expressed by attenuated vaccinia virus protectively immunizes mice. Proceedings of National Academy of Science USA 101, 6641-6646.

Buchholz, U. J., Bukreyev, A., Yang, L., Lamirande, E. W., Murphy, B. R., Subbarao, K., \& Collins, P. L. (2004). Contributions of the structural proteins of severe acute respiratory syndrome coronavirus to protective immunity. Proceedings of National Academy of Science USA 101(26), 9804-9809.

Bukreyev, A., Lamirande, E. W., Buchholz, U. J., Vogel, L. N., Elkins, W. R., St. Claire, M., Murphy, B. R., Subbarao, K., \& Collins, P. L. (2004). Mucosal immunisation of African green monkeys (Cercopithecus aethiops ) with an attenuated parainfluenza virus expressing the SARS coronavirus spike protein for the prevention of SARS. Lancet 363, 2122-2127.

Chen, J. (2020). Pathogenicity and transmissibility of 2019-nCoV-A quick overview and comparison with other emerging viruses. Microbes and Infection 22(2), 69-71.

Chen, W. H., Chag, S. M., Poongavanam, M. V., Biter, A. B., Ewere, E. A., Rezende, W., Seid, C. A., Hudspeth, E. M., Pollet, J., McAtee, C. P., et al. (2017). Optimization of the production process and characterization of the yeast-expressed SARS-CoV recombinant receptor-binding domain (RBD219-N1), a SARS vaccine candidate. Journal of Pharmaceutical Science 106(8), 1961-1970.

Chen, W. H., Du, L., Chag, S. M., Ma, C., Tricoche, N., Tao, X., Seid, C. A., Hudspeth, E. M., Lustigman, S., Tseng, C. T., et al. (2014). Yeast- expressed recombinant protein of the receptor-binding domain in SARS-CoV spike protein with deglycosylated forms as a SARS vaccine candidate. Human Vaccines and Immunotherapy 10(3), 648-658.

Chen, W. H., Strych, U., Hotez, P. J., \& Bottazzi, M. E. (2020). The SARS-CoV-2 Vaccine Pipeline: an Overview. Current Tropical Medicine Reports. https://doi.org/10.1007/s40475-020-00201-6.

Cheung, E. (2020). China coronavirus: Hong Kong researchers have already developed vaccine but need time to test it, expert reveals. South China Morning Post. https://www.scmp.com/news/hong-kong/healthenvironment/article/3047956/china-coronavirus-hong-kong-researchers-have. Accessed 28 Feb 2020.

Chowell, G., Abdirizak, F., Lee, S., Lee, J., Jung, E., Nishiura, H., \& Viboud, C. (2015). Transmission characteristics of MERS and SARS in the healthcare setting: a comparative study. BMC Medicine 13, 210.

Clover Biopharmaceuticals. (2020). Clover initiates development of recombinant subunit-trimer vaccine for Wuhan coronavirus (2019- nCoV). https://pipelinereview.com/index.php/2020012873644/Vaccines/CloverInitiatesDevelopment-of-Recombinant-Subunit-Trimer-Vaccine-for-Wuhan Coronavirus-2019-nCoV.html Accessed online 10 May 2020.

Cyranoski, D. (2020). This scientist hopes to test coronavirus drugs on animals in locked-down Wuhan. Nature 577(7792), 607.

Deming, D., Sheahan, T., Heise, M., Yount, B., Davis, N., Sims, A., Suthar, M., Harkema, J., Whitmore, A., Pickles, R., et al. (2006). Vaccine efficacy in senescent mice challenged with recombinant SARS-CoV bearing epidemic and zoonotic spike variants. PLoS Medicine 3, e525.

Desden, D. (2020). Coronavirus vaccine: Everything you need to know. https://www.medicalnewstoday.com/articles/coronavirus-vaccine. Accessed online 06/04/2020.

Dhama, K., Sharun, K., Tiwari, R., Dadar, M., Malik, Y. S., Singh, K. P., \& Chaicumpa, W. (2020). COVID-19, an emerging coronavirus infection: advances and prospects in designing and developing vaccines, immunotherapeutics, and therapeutics. Human Vaccines and Immunotherapeutics. https://doi.org/10.1080/21645515.2020.1735227.

Elshabrawy, H. A., Coughlin, M. M., Baker, S. C., \& Prabhakar, B. S. (2012). Human monoclonal antibodies against highly conserved HR1 and HR2 domains of the SARS-CoV spike protein are more broadly 
neutralizing. PLoS One 7, e50366.

Enjuanes, L., Dediego, M. L., Alvarez, E., Deming, D., Sheahan, T., \& Baric, R. (2008). Vaccines to prevent severe acute respiratory syndrome coronavirus-induced disease. Virus Research 133(1), 45-62.

Etherington, D. (2020). New coronavirus research suggests vaccines developed to treat it could be long-lasting. https://techcrunch.com/2020/03/25/new-coronavirus-research-suggests-vaccines-developed-totreat-it-could-be-long-lasting/ Accessed online 06/04/2020 12:18 PM

Fast, E., Altman, R. B., \& Chen, B. (2020). Potential T-cell and B-cell Epitopes of 2019-nCoV. bioRxiv. doi: https://doi.org/10.1101/2020.02.19.955484

Gillim-Ross, L., \& Subbarao, K. (2006). Emerging Respiratory Viruses: Challenges and Vaccine Strategies. Clinical Microbiological Review 19(4), 614-636.

Glaxo Smith Kline press release on 2/24/2020. https://www.gsk. com/en-gb/media/press-releases/cloverand-gsk-announce-research-collaboration-to-evaluate-coronavirus-covid-19-vaccine-candidate-withpandemic-adjuvant-system.

Gorbalenya, A. E., Baker, S. C., Baric, R. S., de Groot, R. J., Drosten, C., Gulyaeva, A. A., Haagmans, B. L., Lauber, C., Leontovich, A. M., Neuman, B. W., et al. (2020). The species severe acute respiratory syndrome-related coronavirus: classifying 2019-nCoV and naming it SARS-CoV-2. Nature Microbiology 5, 536-544.

Graham, R. L., Becker, M. M., Eckerle, L. D., Bolles, M., Denison, M. R., \& Baric, R. S. (2012). A live, impaired-fidelity coronavirus vaccine protects in an aged, immunocompromised mouse model of lethal disease. Nature Medicine 18, 1820-1826.

Graham, R. L., Donaldson, E. F., \& Baric, R. S. (2013). A decade after SARS: strategies for controlling emerging coronaviruses. Nature Reviews Microbiology 11(12), 836-848.

Gralinski, L. E., \& Baric, R. S. (2015). Molecular pathology of emerging coronavirus infections. Journal of Pathology 235(2), 185-195.

Guan, W., Ni, Z., Hu, Y., Liang, W., Ou, C., He, J., Liu, L., Shan, H., Lei, C., Hui, D. S., et al. (2020). Clinical characteristics of 2019 novel coronavirus infection in China. New England Journal of Medicine 382, 1708-1720.

He, H., Tang, Y., Qin, X., Xu, W., Wang, Y., Liu, X., Liu, X., Xiong, S., Li, J., Zhang, M., \& Duan, M. ( 2005b). Construction of a eukaryotic expression plasmid encoding partial S gene fragments of the SARS-CoV and its potential utility as a DNA vaccine. DNA Cell Biology 24(8), 516-520.

He, Y., Zhou, Y., Siddiqui, P., Niu, J., \& Jiang, S. (2005a). Identification of immunodominant epitopes on the membrane protein of the severe acute respiratory syndrome-associated coronavirus. Journal of Clinical Microbiology 43, 3718-3726.

Hoffmann, M., Kleine-Weber, H., Kruger, N., Muller, M., Drosten, C., \& Pohlmann, S. (2020). The novel coronavirus 2019 (2019-nCoV) uses the SARS-coronavirus receptor ACE2 and the cellular protease TMPRSS2 for entry into target cells. bioRxiv. https://doi.org/10.1101/2020.01.31.929042.

Hu, Z., Song, C., Xu, C., Jin, G., Chen, Y., Xu, X., Ma, H., Chen, W., Lin, Y., Zheng, Y., et al. (2020). Clinical characteristics of 24 asymptomatic infections with COVID-19 screened among close contacts in Nanjing, China. Science China Life Science 63(5), 706-711.

Huang, C., Wang, Y., Li, X., Ren, L., Zhao, J., Hu, Y., Zhang, L., Fan, G., Xu, J., Gu, X., et al. (2020). Clinical features of patients infected with 2019 novel coronavirus in Wuhan, China. Lancet 395(10223), 497-506. 
Hui, D. S., I Azhar, E., Madani, T. A., Ntoumi, F., Kock, R., Dar, O., Ippolito, G., Mchugh, T. D., Memish, Z. A., Drosten, C., et al. (2020). The continuing 2019-nCoV epidemic threat of novel coronaviruses to global health - The latest 2019 novel coronavirus outbreak in Wuhan, China. International Journal of Infectious Diseases 91, 264-266.

J\&J. (2020). working on coronavirus vaccine. The pharma letter. https:// www.thepharmaletter.com/article/j-j-working-on-coronavirus- vaccine. Accessed 28 Feb 2020.

Jahanafrooz, Z., Baradaran, B., Mosafer, J., Hashemzaei, M., Rezaei, T., Mokhtarzadeh, A., \& Hamblin, M. R. (2020). Comparison of DNA and mRNA vaccines against cancer. Drug Discovery Today 25, 552-560.

Jaume, M., Yip, M. S., Kam, Y. W., Cheung, C. Y., Kien, F., Roberts, A., Li, P. H., Dutry, I., Escriou, N., Daeron, M., et al. (2012). SARS CoV subunit vaccine: antibody-mediated neutralisation and enhancement. Hong Kong Medical Journal 18(2), 31-36.

Jiaming, L., Yanfeng, Y., Yao, D., Yawei, H., Linlin, B., Baoying, H., Jinghua, Y., Gao, G. F., Chuan, Q., \& Wenjie, T. (2017). The recombinant N-terminal domain of spike proteins is a potential vaccine against Middle East respiratory syndrome coronavirus (MERS-CoV) infection. Vaccine 35(1), 10-18.

Jiang, S., Bottazzi, M. E., Du, L., Lustigman, S., Tseng, C. T., Curti, E., Jones, K., Zhan, B., \& Hotez, P. J. (2012). Roadmap to developing a recombinant coronavirus S protein receptor-binding domain vaccine for severe acute respiratory syndrome. Expert Reviews of Vaccines 11(12), 1405-1413.

Jiang, S., Du, L., \& Shi, Z. (2020). An emerging coronavirus causing pneumonia outbreak in Wuhan, China: calling for developing therapeutic and prophylactic strategies. Emerging Microbes and Infection 9(1), 275-277.

Jiang, S., He, Y., \& Liu, S. (2005). SARS vaccine development. Emerging Infectious Diseases 11, 1016-1020.

Jin, H., Xiao, C., Chen, Z., Kang, Y., Ma, Y., Zhu, K., Xie, Q., Tu, Y., Yu, Y., \& Wang, B. (2005). Induction of Th1 type response by DNA vaccinations with N, M, and E genes against SARS-CoV in mice. Biochemical and Biophysical Research Communication 328(4), 979-986.

Kim, E., Erdos, G., Huang, S., Kenniston, T. W., Balmert, S. C., Carey, C. D., Raj, V. S., Epperly, M. W., Klimstra, W. B., Haagmans, B. L., et al. (2020). Microneedle array delivered recombinant coronavirus vaccines: Immunogenicity and rapid translational development. EBioMedicine. https://doi.org/10.1016/j.ebiom.2020.102743.

Kim, M. H., Kim, H. J., \& Chang, J. (2019). Superior immune responses induced by intranasal immunization with recombinant adenovirus-based vaccine expressing full-length spike protein of Middle East respiratory syndrome coronavirus. PLoS One 14(7), e0220196.

Kim, T. W., Lee, J. H., Hung, C. F., Peng, S., Roden, R., Wang, M. C., Viscidi, R., Tsai, Y. C., He, L., Chen, P. J., et al. (2004). Generation and characterization of DNA vaccines targeting the nucleocapsid protein of severe acute respiratory syndrome coronavirus. Journal of Virology 78, 4638-4645.

Krammer, F., Margine, I., Tan, G. S., Pica, N., Krause, J. C., \& Palese, P. (2012). A carboxy-terminal trimerization domain stabilizes conformational epitopes on the stalk domain of soluble recombinant hemagglutinin substrates. PloS One 7(8), e43603.

Kupferschmidt, K., \& Cohen, J. (2020). Will novel virus go pandemic or be contained? Science 367(6478), 610-611.

Lan, J., Ge, J., Yu, J., Shan, S., Zhou, H., Fan, S., Zhang, Q., Shi, X., Wang, Q., Zhang, L., et al. (2020). Crystal structure of the 2019-nCoV spike receptor-binding domain bound with the ACE2 receptor. BioRxiv. doi: https://doi.org/10.1101/2020.02.19.956235.

Leung, D. T., Tam, F. C., Ma, C. H., Chan, P. K., Cheung, J. L., Niu, H., Tam, J. S., Lim, P. L. (2004). Antibody response of patients with severe acute respiratory syndrome (SARS) targets the viral nucleocapsid. 
Journal of Infectious Diseases 190, 379-386.

Li, E., Yan, F., Huang, P., Chi, H., Xu, S., Li, G., Liu, C., Feng, N., Wang, H., \& Zhao, Y. Y. (2020). Characterization of the immune response of MERS-CoV vaccine candidates derived from two different vectors in mice. Viruses 12(1), E125.

Li, J., Ulitzky, L., Silberstein, E., Taylor, D. R., \& Viscidi, R. (2013). Immunogenicity and protection efficacy of monomeric and trimeric recombinant SARS coronavirus spike protein subunit vaccine candidates. Viral Immunology 26(2), 126-132.

Liu, C., Zhou, Q., Li, Y., Garner, L. V., Watkins, S. P., Carter, L. J., Smoot, J., Gregg, A. C., Daniels, A. D., Jervey, S., \& Albaiu, D. (2020). Research and Development on Therapeutic Agents and Vaccines for COVID-19 and Related Human Coronavirus Diseases. ACS Central Science 6, 315-331.

Liu, H., Su, D., Zhang, J., Ge, S., Li, Y., Wang, F., Gravel, M., Roulston, A., Song, Q., Xu, W., et al. (2017). Improvement of Pharmacokinetic Profile of TRAIL via Trimer-Tag Enhances its Antitumor Activity in vivo. Scientific Reports 7(1), 8953.

Liu, J., Sun, Y., Qi, J., Chu, F., Wu, H., Gao, F., Li, T., Yan, J., Gao, G. F. (2010). The membrane protein of severe acute respiratory syndrome coronavirus acts as a dominant immunogen revealed by a clustering region of novel functionally and structurally defined cytotoxic T-lymphocyte epitopes. Journal of Infectious Diseases 202, 1171-1180.

Liu, L., Wei, Q., Lin, Q., Fang, J., Wang, H., Kwok, H., Tang, H., Nishiura, K., Peng, J., Tan, Z., et al. (2019). Anti-spike IgG causes severe acute lung injury by skewing macrophage responses during acute SARS-CoV infection. JCI Insight 4(4), 123158.

Liu, M. A. (2019). A Comparison of Plasmid DNA and mRNA as Vaccine Technologies. Vaccines 7(2), E37.

Liu, S. J., Leng, C. H., Lien, S. P., Chi, H. Y., Huang, C. Y., Lin, C. L., Lian, W. C., Chen, C. J., Hsieh, S. L., \& Chong, P. (2006). Immunological characterizations of the nucleocapsid protein based SARS vaccine candidates. Vaccine 24(16), 3100-3108.

Liu, W. J., Zhao, M., Liu, K., Xu, K., Wong, G., Tan, W., \& Gao, G. F. (2017). T-cell immunity of SARS-CoV: Implications for vaccine development against MERS-CoV. Antiviral Research 137, 82-92.

Liu, X., Shi, Y., Li, P., Li, L., Yi, Y., Ma, Q., \& Cao, C. (2004). Profile of antibodies to the nucleocapsid protein of the severe acute respiratory syndrome (SARS)-associated coronavirus in probable SARS patients. Clinical and Vaccine Immunology 11(1), 227-228.

Liu, Y., Gayle, A. A., Wilder-Smith, A., \& Rocklov, J. (2020). The reproductive number of COVID-19 is higher compared to SARS coronavirus. Journal of Travel Medicine 27(2). https://doi.org/10.1093/jtm/taaa021.

Marohn, M. E., \& Barry, E. M. (2013). Live attenuated tularemia vaccines: Recent developments and future goals. Vaccine 31, 3485-3491.

McBride, R., van Zyl, M., \& Fielding, B. C. (2014). The coronavirus nucleocapsid is a multifunctional protein. Viruses 6, 2991-3018.

Minor, P. D. (2015). Live attenuated vaccines: Historical successes and current challenges. Virology 479-480, 379-392.

Moderna press release on 2/24/2020. https://investors. modernatx.com/news-releases/news-releasedetails/moderna-ships- mrna-vaccine-against-novel-coronavirus-mrna-1273.

Morse, J. S., Lalonde, T., Xu, S., \& Liu, W. (2020). Learning from the past: possible urgent prevention and treatment options for severe acute respiratory infections caused by 2019-nCoV. Chemistry and Biochemistry 21(5), 730-738. 
Neher, R. A., Dyrdak, R., Druelle, V., Hodcroft, E. B., \& Albert, J. (2020). Potential impact of seasonal forcing on a SARS-CoV-2 pandemic. Swiss Medical Weekly 150, w20224.

Neuman, B. W., Kiss, G., Kunding, A. H., Bhella, D., Baksh, M. F., Connelly, S., Droese, B., Klaus, J. P., Makino, S., Sawicki, S. G., et al. (2011). A structural analysis of M protein in coronavirus assembly and morphology. Journal of Structural Biology 174(1), 11-22.

Ng, O. W., Chia, A., Tan, A. T., Jadi, R. S., Leong, H. N., Bertoletti, A., \& Tan, Y. J. (2016). Memory T cell responses targeting the SARS coronavirus persist up to 11 years post-infection. Vaccine 34, 2008-2014.

Ng, O. W., \& Tan, Y. J. (2017). Understanding bat SARS-like coronaviruses for the preparation of future coronavirus outbreaks - Implications for coronavirus vaccine development. Human Vaccines and Immunotherapeutics 13(1), 186-189.

Nieto-Torres, J. L., DeDiego, M. L., Verdia-Baguena, C., Jimenez-Guardeno, J. M., Regla-Nava, J. A., Fernandez-Delgado, R., Castano-Rodriguez, C., Alcaraz, A., Torres, J., Aguilella, V. M., et al. (2014). Severe acute respiratory syndrome coronavirus envelope protein ion channel activity promotes virus fitness and pathogenesis. PLoS Pathogens 10, e1004077.

Novavax press release on 2/26/2020. http://ir.novavax.com/news-releases/news-release-details/novavaxadvances-development- novel-covid-19-vaccine.

Pang, H., Liu, Y., Han, X., Xu, Y., Jiang, F., Wu, D., Kong, X., Bartlam, M., \& Rao, Z. (2004). Protective humoral responses to severe acute respiratory syndrome-associated coronavirus: Implications for the design of an effective protein-based vaccine. Journal of General Virology 85, 3109-3113.

Pardi, N., Hogan, M. J., Porter, F. W., \& Weissman, D. (2018). mRNA vaccines- A new era in vaccinology. Nature Reviews Drug Discovery 17, 261-279.

Perlman, S. (2020). Another decade, another coronavirus. New England Journal of Medicine 382, 760-762.

Rappuoli, R., Black, S., \& Bloom, D. E. (2019). Vaccines and global health: In search of a sustainable model for vaccine development and delivery. Science Translational Medicine 11(497), eaaw2888.

Rauch, S., Jasny, E., Schmidt, K. E., \& Petsch, B. (2018). New vaccine technologies to combat outbreak situations. Frontiers in Immunology 9, 1963.

Remy, V., Largeron, N., Quilici, S., \& Carroll, S. (2014). The economic value of vaccination: Why prevention is wealth. Value in Health 17(7), A450.

Roper, R. L., \& Rehm, K. E. (2016). SARS vaccines: where are we? Expert Reviews of Vaccines 8(7), 887-898.

Rothe, C., Schunk, M., Sothmann, P., Bretzel, G., Froeschl, G., Wallrauch, C., Zimmer, T., Thiel, V., Janke, C., Guggemos, W., et al. (2020). Transmission of 2019-nCoV infection from an asymptomatic contact in Germany. New England Journal of Medicine 382, 970-971.

Ryan, J. (2020). Coronavirus vaccines: Drug trials, chloroquine and treatments for COVID19. https://www.cnet.com/how-to/coronavirus-vaccines-drug-trials-chloroquine-and-treatments-for-covid19/ Accessed online 06/04/2020.

Saif, L. J. (2017). Coronaviruses of domestic livestock and poultry: Interspecies transmission, pathogenesis and immunity, In: Perlman S, Holmes K. (eds), Nidovirales, Washington, DC: American Society of Microbiology, pp 279-98.

Saif, L. J. (2020). Vaccines for COVID-19: Perspectives, Prospects, and Challenges Based on Candidate SARS, MERS, and Animal Coronavirus Vaccines. European Medical Journal. https://doi.org/10.33590/emj/200324. 
Schindewolf, C., \& Menachery, V. D. (2019). Middle east respiratory syndrome vaccine candidates: cautious optimism. Viruses 11(1), E74.

Sharma, A., Krause, A., \& Worgall, S. (2011). Recent developments for Pseudomonas vaccines. Human Vaccines 7, 999-1011.

Shi, J., Zhang, J., Li, S., Sun, J., Teng, Y., Wu, M., Li, J., Li, Y., Hu, N., Wang, H., et al. (2015). Epitope-based vaccine target screening against highly pathogenic MERS-CoV: an in silico approach applied to emerging infectious diseases. PLoS One 10(12), e0144475.

Shieber, J. (2020). Codagenix raises $\$ 20$ million for a new flu vaccine and other therapies. Tech Crunch. https://techcrunch.com/2020/01/13/codagenix-raises-20-million-for-a-new-flu vaccine-and-other- therapies/ Accessed 28 Feb 2020.

Stadler, K., Roberts, A., Becker, S., Vogel, L., Eickmann, M., Kolesnikova, L., Klenk, H. D., Murphy, B., Rappuoli, R., Abrignani, S., \& Subbarao, K. ( 2005). SARS vaccine protective in mice. Emerging Infectious Diseases 11, 1312-1314.

Tang, F., Quan, Y., Xin, Z. T., Wrammert, J., Ma, M. J., Lv, H., Wang, T. B., Yang, H., Richardus, J. H., Liu, W., et al. (2011). Lack of peripheral memory B cell responses in recovered patients with severe acute respiratory syndrome: A six-year follow-up study. Journal of Immunology 186, 7264-7268.

Tang, X., Wu, C., Li, X., Song, Y., Yao, X., Wu, X., Duan, Y., Zhang, H., Wang, Y., \& Qian, Z. (2020). On the origin and continuing evolution of SARS-CoV-2. National Science Review. https://doi.org/10.1093/nsr/nwaa036.

Tian, X., Li, C., Huang, A., Xia, S., Lu, S., Shi, Z., Lu, L., Jiang, S., Yang, Z., Wu, Y., et al. (2020). Potent binding of 2019 novel coronavirus spike protein by a SARS coronavirus-specific human monoclonal antibody. Emerging Microbes and Infection 9, 382-385.

Vlasova, A. N., Kandasamy, S., \& Saif, L. J. (2016). "Gnotobiotic neonatal pig model of rotavirus infection and disease" In: Svensson L, Desselberger U, Estes MK (eds). Viral gastroenteritis: molecular epidemiology and pathogenesis. The Netherlands: Elsevier, pp 219-241.

Wan, Y., Shang, J., Sun, S., Tai, W., Chen, J., Geng, Q., He, L., Chen, Y., Wu, J., Shi, Z., et al. (2020). Molecular Mechanism for Antibody-Dependent Enhancement of Coronavirus Entry. Journal of Virology 94(5), e02015-19.

Wang, N, Shang, J., Jiang, S., \& Du, L. (2020). Subunit vaccines against emerging pathogenic human coronaviruses. Frontiers in Microbiology 11, 298. https://doi.org/10.3389/fmicb.2020.00298.

Wang, Q., Zhang, L., Kuwahara, K., Li, L., Liu, Z., Li, T., Zhu, H., Liu, J., Xu, Y., Xie, J., et al. (2016). Immunodominant SARS coronavirus epitopes in humans elicited both enhancing and neutralizing effects on infection in non-human primates. ACS Infectious Diseases 2, 361-376.

Woo, P. C., Lau, S. K., Tsoi, H. W., Chen, Z. W., Wong, B. H., Zhang, L., Chan, J. K., Wong, L. P., He, W., Ma, C., et al. (2005). SARS coronavirus spike polypeptide DNA vaccine priming with recombinant spike polypeptide from Escherichia coli as booster induces high titer of neutralizing antibody against SARS coronavirus. Vaccine 23(42), 4959-4968.

World Health Organization (2020). Coronavirus disease (COVID-2019) R\&D. Available at: https://www.who.int/blueprint/priority-diseases/key-action/novel-coronavirus/en/. Last Accessed: 13 March 2020.

Worldometer. (2020). https://www.worldometers.info/coronavirus/ Accessed online 20/05/2020 12:12 PM.

Wrapp, D., Wang, N., Corbett, K. S., Goldsmith, J. A., Hsieh, C. L., Abiona, O., Graham, B. S., \& McLellan, J. S. (2020). Cryo-EM structure of the 2019-nCoV spike in the prefusion conformation. Science 367(6483), $1260-1263$. 
Wrapp, D., Wang, N., Corbett, K. S., Goldsmith, J. A., Hsieh, C. L., Abiona, O., Graham, B. S., \& McLellan, J. S. (2020). Cryo-EM structure of the 2019-nCoV spike in the prefusion conformation. Science 2011, eabb2507.

Wu, J. T., Leung, K., \& Leung, G. M. (2020). Nowcasting and forecasting the potential domestic and international spread of the 2019-nCoV outbreak originating in Wuhan, China: A modelling study. Lancet 395(10225), 689-697.

Xie, Q., He, X., Yang, F., Liu, X., Li, Y., Liu, Y., Yang, Z., Yu, J., Zhang, B., \& Zhao, W. (2018). Analysis of the genome sequence and prediction of B-cell epitopes of the envelope protein of Middle East respiratory syndrome-coronavirus. IEEE/ACM Transactions on Computational Biology and Bioinformatics 15(4), 1344-1350.

Yao, H., Lu, X., Chen, Q., Xu, K., Chen, Y., Cheng, L., Liu, F., Wu, Z., Wu, H., Jin, C., et al. (2020). Patient-derived mutations impact pathogenicity of SARS-CoV-2. MedRxiv https://doi.org/10.1101/2020.04.14.20060160

Yu, F., Du, L., Ojcius, D. M., Pan, C., \& Jiang, S. (2020). Measures for diagnosing and treating infections by a novel coronavirus responsible for a pneumonia outbreak originating in Wuhan, China. Microbes and Infection 22(2), 74-79.

Yu, W. B., Tang, G. D., Zhang, L., \& Corlett, R. T. (2020). Decoding evolution and transmissions of novel pneumonia coronavirus (SARS-CoV-2) using the whole genomic data. Zoological Research. 1-11. https://doi.org/10.24272/j.issn.2095-8137.2020.022.

Zakhartchouk, A. N., Liu, Q., Petric, M., \& Babiuk, L. A.( 2005). Augmentation of immune responses to SARS coronavirus by a combination of DNA and whole killed virus vaccines. Vaccine 23(35), 4385-4391.

Zaki, A. M., van Boheemen, S., Bestebroer, T. M., Osterhaus, A. D., \& Fouchier, R. A. (2012). Isolation of a novel coronavirus from a man with pneumonia in Saudi Arabia. New England Journal of Medicine 367(19), 1814-1820.

Zhang, J., Zeng, H., Gu, J., Li, H., Zheng, L., \& Zou, Q. (2020). Progress and Prospects on Vaccine Development against SARS-CoV-2. Vaccines 8(2), 153. https://doi.org/10.3390/vaccines8020153.

Zhang, L., \& Liu, Y. (2020). Potential interventions for novel coronavirus in China: a systemic review. Journal of Medical Virology 92(5), 479-490.

Zheng, N., Xia, R., Yang, C., Yin, B., Li, Y., Duan, C., Liang, L., Guo, H., \& Xie, Q. (2009). Boosted expression of the SARS-CoV nucleocapsid protein in tobacco and its immunogenicity in mice. Vaccine 27(36), 5001-5007.

Zhou, P., Yang, X.L., Wang, X. G., Hu, B., Zhang, L., Zhang, W., Si, H. R., Zhu, Y., Li, B., Huang, C. L., et al. (2020). A pneumonia outbreak associated with a new coronavirus of probable bat origin. Nature 579, 270-273.

Zhou, Y., Jiang, S., \& Du, L. (2018). Prospects for a MERS-CoV spike vaccine. Expert Reviews of Vaccines 17, 677-686.

Zhou, Y., Yang, Y., Huang, J., Jiang, S., \& Du, L. (2019). Advances in MERS-CoV vaccines and therapeutics based on the receptor-binding domain. Viruses 11(1), E60.

Zhu, N., Zhang, D., Wang, W., Li, X., Yang, B., Song, J., Zhao, X., Huang, B., Shi, W., Lu, R., et al. (2020). A novel coronavirus from patients with pneumonia in China, 2019. New England Journal of Medicine 382(8), 727-733.

Zhu, X., Liu, Q., Du, L., Lu, L., \& Jiang, S. (2013). Receptor-binding domain as a target for developing SARS vaccines. Journal of Thoracic Diseases 5(2), S142-S148. 